RUNNING HEAD: Fabricated Memories

\title{
Intentionally Fabricated Autobiographical Memories
}

Lucy V. Justice ${ }^{1}$, Catriona M. Morrison ${ }^{2}, \&$ Martin A. Conway ${ }^{3}$

${ }^{1}$ Division of Psychology, Nottingham Trent University, Nottingham, England

${ }^{2}$ Division of Psychology, University of Bradford, Bradford, England

${ }^{3}$ Department of Psychology, City University, London, England

Address for correspondence:

Professor Martin A. Conway

Department of Psychology

City University London,

Northampton Square,

London, EC1V 0HB

Email: martinconway1@me.com 


\begin{abstract}
$\underline{\text { Abstract }}$
Participants generated both autobiographical memories (AMs) that they believed to be true and intentionally fabricated autobiographical memories (IFAMs). Memories were constructed while a concurrent memory load (random 8-digit sequence) was held in mind or while there was no concurrent load. Amount and accuracy of recall of the concurrent memory load was reliably poorer following generation of IFAMs relative to AMs. There was, however, no reliable effect of load on memory generation times however IFAMs always took longer to construct than AMs. Finally, replicating previous findings, fewer IFAMs had a field perspective than AMs, IFAMs were less vivid than AMs, and IFAMs contained more motion words (indicative of increased cognitive load). Taken together these findings show a pattern of systematic differences that mark out IFAMs and they also show that IFAMs can be identified indirectly by lowered performance on concurrent tasks that increase cognitive load.
\end{abstract}

Keywords: autobiographical memory, false memories, executive processes, memory perspective, linguistic analysis, cognitive load, concurrent tasks.

Word count: 3121 (excluding references) 


\section{$\underline{\text { Introduction }}$}

In a study that contrasted the construction of autobiographical memories (AMs: memories that are believed to be true) with intentionally false autobiographical memories (IFAMs: memories that are entirely or partially deliberately fabricated, consisting mainly but not exclusively of false facts as oppose to false opinions or beliefs) it was proposed that the generation of IFAMs was cognitively more demanding than the construction of AMs, (Justice, Morrison, \& Conway, 2013; see too Vrij, Fisher, Mann, \& Leal, 2008). Indeed, Justice et al. (2013) found that a common strategy in IFAM generation was to construct an AM and then delete details and/or add false details. Such a strategy includes an additional "delete-substitute" editing phase following AM construction and therefore draws more heavily on cognitive resources, (see too, Polage, 2004, for similar suggestions relating to lying).

One model of autobiographical memory holds that memory construction takes place through a process of cyclic access and evaluation, under executive control, of long-term autobiographical knowledge and episodic memories (Conway \& PleydellPearce, 2000; Conway, 2005; Conway, 2009). This construction process iteratively establishes a pattern of activation across distributed and complex neural networks in which autobiographical memories are represented (see Cabeza \& St Jacques, 2007, for review). Thus, whatever the form the additional editing processes take in IFAM construction, these will only add to what is already a complex and lengthy cognitive process. Indeed, the notion that fabricated memories/lies are more cognitively demanding than truthful recall/narrative is not a new one, and has been noted and discussed in a number of recent studies (Blandón-Gitlin, Fenn, Masip, \& Yoo, 2014; Vrij et al., 2008; Vrij, 2014; Walczyk et al., 2005; Walczyk, Igou, Dixon, \& Tcholakian, 
2013). There is, however, very little in the way of empirical evidence supporting the conjecture that fabricated memories and lies are more cognitively demanding. The present work aimed, then, to provide a quantitative understanding of the cognitive demands associated with generating IFAMs. One prediction is that if the requirements of control processing capacity are increased this should impact more on the construction of IFAMs than AMs. In order to test this it was decided to investigate AM and IFAM construction with and without a concurrent memory load. If there is an additional "edit" phase in IFAM construction then concurrent memory load should impact more on IFAM construction than and AM construction. This impact should be detected in poorer secondary task performance and in generation times during IFAM generation. In contrast, post construction factors should show broadly the same pattern of differences as those reported in Justice, et al., (2013). Specifically, we expect IFAMs to be reported as less vivid, to have a longer retention interval i.e. be placed further in the past, to contain more 'motion words', such as "walk", "go", "run" and to take on an observer perspective more often than field perspective, as compared to AMs. These patterns of findings, we concluded in Justice, et al., (2013) indicated a process of IFAM generation that was more effortful than AM generation and that this increased effort was due to an increased cognitive load due to the additional phase of "editing". In the current study therefore, we aim to empirically investigate the existence of the editing phase and ask whether a demanding secondary task can be a useful tool for distinguishing IFAMs from AMs.

\section{$\underline{\text { Methods }}$}

Participants. Thirty-one volunteers took part, 19 females and 12 males. Ages ranged from 19 to 37 years, with a mean of 25. Participants received a small payment. 
Figures $1 \& 2$ about here

Materials and Procedure. A cued recall procedure was used and Figures 1 and 2 show the presentation order of cues and ratings for each trial for both conditions, "no concurrent memory load" and "concurrent memory load". Participants were tested individually. Instructions and materials were presented on a computer. There were 16 cues naming common everyday activities, (taken from Justice, et al., 2012), e.g. "going to a restaurant", see appendix 1 for full list. Cues were randomly assigned to four blocks each with four trials. Presentation order was counterbalanced across participants and conditions, ensuring that all cues were used to generate both IFAMs and AMs and under both load and no load conditions. In one block of four cues participants were instructed to recall whilst holding a number in mind, a second required them to recall without holding a number in mind, a third required them to imagine (an IFAM) whilst holding a number in mind, and in the fourth participants imagined (an IFAM) without holding a number in mind. There was a short 2-mimute pause between blocks while the instructions defining the next block of trials were reviewed.

Participants were presented with a screen displaying one of the following instructions depending on that block of trials: "RECALL WITH NUMBER", “RECALL NO NUMBER”, “IMAGINE WITH NUMBER” or “IMAGINE NO NUMBER". The space bar was pressed to initiate a trial. For recall and imagine without concurrent memory load conditions a cue was displayed that remained on the screen until the participant indicated, by pressing the space bar, that they had retrieved a 
memory, or fabricated a memory to the cue. For recall and imagine with concurrent memory load participants were presented, on each trial, with a randomly generated sequence of 8-digits for 2000ms (Gil-Gomez de Liano \& Botella, 2010; Heaver \& Hutton, 2011) immediately prior to presentation of the cue. Participants were instructed to hold this number in mind whilst generating a memory/imagining and to then enter the number, on a separate screen that was displayed following memory generation. Participants were instructed to be as accurate as possible when entering the number and in particular to remember the correct sequence or at least enter the numbers they recalled in the boxes on the screen in roughly the place they felt they had originally been presented.

For AMs and IFAMs participants were instructed, according to the requirement for that block of trials, that in response to the cue they should recall a memory they believed to be true or imagine an event they knew to be false. They were to do so as quickly as possible but ensure they had a specific AM or IFAM in mind. As soon as they had generated a detailed memory or imagined a fabricated past event they pressed the space bar. Participants were instructed to ensure all fabricated events occurred in the past and to describe them as if they were trying to convince another person that the event had actually been experienced. For AMs they were instructed to bring to mind a memory of an event which they had directly experienced that had lasted for minutes or hours but no longer than one day. Both types of memory could be recalled or located at any point in their own personal past.

$\mathrm{AM}$ and IFAM generation times were recorded in milliseconds from cue on-screen to space bar press. After a memory had been provided, participants rated the vividness 
of AMs and IFAMs using a 7-point scale (1=low, 7=high), and indicated the perspective or point-of-view in their memory: they were instructed to judge a memory as having an "observer" perspective if they saw themselves in the memory and to judge a "field" perspective if they had something approximating to their original perspective or what would have been their original perspective for an IFAM. They were asked to judge the approximate age at which the memory had occurred. For IFAMs they were instructed to plausibly fabricate a date. Finally they typed the details of their AM/IFAM. 


\section{$\underline{\text { Results }}$}

The results are reported in two sections. The first examines performance on the secondary task, amount and accuracy of recall of the concurrent 8-digit load. The second reports the analysis of the memory variables.

\section{Concurrent Memory Load}

Manipulation Check. Performance on the concurrent task was assessed by examining the number of trials on which digits were entered correctly, regardless of order accuracy. It was found that $97 \%$ of trials resulted in participants correctly recalling six digits or more while concurrently generating an AM, whereas only $90 \%$ of trials resulted in participants recalling six or more digits while generating an IFAM. This difference was not significant. In contrast, however, it was found that in $76 \%$ of trials participants correctly recalled eight digits, in any order, whilst concurrently recalling an $\mathrm{AM}$ as compared to $55 \%$ of trials in which participants recalled eight digits when generating an IFAM, $\chi^{2}(1, N=31)=4.1, \mathrm{p}<0.05$. These results show that cognitive load impacts the generation of IFAMs more than the generation of AMs and further confirms that participants were following instructions, completing the secondary task as required.

The results are reported in two sections. The first examines performance on the secondary task, amount and accuracy of recall of the concurrent 8-digit load. The second reports the analysis of the memory variables.

\section{Concurrent Memory Load}




\section{Figures $3 \& 4$ about here}

Accuracy of Recall. For this analysis, recall of the full sequence of 8 digits was scored as correct only if they were recalled in the originally presented serial order. Thus, in any given block of trials a maximum of 4 correct recalls was possible (no participant attained this level of accuracy). It was found that reliably fewer sequences were in correct serial order following IFAM generation $(m=0.65$, S.D. 1.2) than after recalling an AM, $(\mathrm{m}=1.6$, S.D. 0.8), $\mathrm{t}(1,30)=5.0, \mathrm{p}<0.001, \mathrm{~d}=0.9$. After generating an IFAM, then, participants recalled the entire original number in correct serial order in only $16 \%$ of their trials, whereas after remembering AMs, participants entered the entire original number in correct serial order in $40 \%$ of their trials, see figure 3.

Finally, the time taken to enter the recalled numbers was recorded in milliseconds from key press to indicate a memory had been generated to space bar press to indicate the last digit had been entered. For analysis, all reaction time data reported were transformed using a log base 10 calculation to normalise the distribution and minimise the effect of extreme data points. Participants took reliably longer to input their numbers after generating an IFAM (9554ms, S.D. 3079ms) than after retrieving an AM (8155ms, S.D. $3051 \mathrm{~ms}), t(1,30)=4.2, \mathrm{p}<0.01, d=0.5$. Taken together these differences show that IFAM generation impaired performance on the secondary task relative to AM generation, see figure 4.

\section{$\underline{\text { Memory Variables }}$}

Table 1 about here 
Table 1 shows the means and S.D.s for six variables. Memory retrieval/image generation times in milliseconds (top row of Table 1) were analysed using a 2 (AM or IFAM) x 2 (load or no load) repeated measures ANOVA. A main effect of condition was observed such that IFAMs took significantly longer to generate than AMs, $F(1$, $30)=5.2, \underline{\mathrm{MS}_{\mathrm{e}}}=17028741, \mathrm{p}<0.05, \eta_{\mathrm{p}}{ }^{2}=0.14$. Thus, IFAM generation took reliably longer than AM construction whether or not there was a concurrent memory load. Two recollective qualities, vividness and retention interval, (Table $1,2^{\text {nd }}$ and $3^{\text {rd }}$ rows) were entered into separate $2 \times 2$ repeated measures ANOVAs identical to that use for generation times. A main effect of vividness was observed, $\left(F(1,30)=24.0, \underline{M S}_{\mathrm{e}}=1.3\right.$, $\left.\mathrm{p}<0.001, \eta_{\mathrm{p}}{ }^{2}=0.4\right)$, showing that IFAMs were reliably less vivid than AMs. No other reliable differences were found.

Table 2 about here

Memory perspective, field vs. observer, was examined. Table 2 shows that $75 \%$ of AMs had a field perspective (the participant sees the memory through their own eyes) and the remaining $25 \%$ had an observer perspective (the participant sees themselves in the memory). For IFAMs $45 \%$ had an observer perspective with $54 \%$ having a field perspective. These differences in perspective between AMs and IFAMs were found to be reliable overall, $\left(\chi^{2}(1, N=31)=44.7, \mathrm{p}<0.001\right)$. Following Justice, et al., (2012) memory accounts were analysed for three linguistic constructs (Table 1, lower 3 rows): motion words, account length and six letter words. The counts were made using the Linguistic Inquiry and Word Count, LIWC, program (Pennebaker, Francis, \& Booth, 2001) and were subsequently entered into separate 2 (AM/IFAM) x 2 (Load/No Load) repeated measures ANOVAs. A main effect of memory type was found for motion 
words $\left(\mathrm{F}(1,30)=4.3, \mathrm{MSe}=1.0, \mathrm{p}<0.05, \eta_{\mathrm{p}}{ }^{2}=0.1\right)$, showing that IFAM accounts contained reliably more motion words $(\mathrm{MD}=-0.4, \mathrm{p}<0.05)$ than $\mathrm{AM}$ accounts. No other differences were reliable. This pattern of differences in perspective and linguistics between AMs and IFAMs is highly consistent with the findings of Justice et al. (2012).

\section{$\underline{\text { Discussion }}$}

The present experiment investigated the proposal that the generation of IFAMs is more cognitively demanding than the generation of AMs and, specifically, utilises executive control processes more than AMs. A secondary task, concurrent memory load, that draws on central processing capacity should, according to this view, be more difficult when generating IFAMs. And, as a corollary, IFAM generation itself should be attenuated while performing the secondary task. Performance in recalling a concurrent digit load was indeed found to be impaired when the load was held in mind while IFAMs were generated. This impairment was reflected in the lower amount and lower serial recall of the concurrent digit load following IFAM generation compared to recall levels following AM generation. This, then, supports the proposal that IFAM generation loads more heavily on central processing resources than does AM generation.

The findings for the memory variables were, however, less conclusive with respect to cognitive load but, nonetheless, highly consistent with previous findings of differences between IFAMs and AMs. For example, IFAMs took reliably longer to retrieve than AMs regardless of concurrent memory load. Nevertheless, IFAMs with concurrent memory load took far longer to generate than any other memories and were nearly 2s longer than IFAMs with no concurrent load (see Table 1). The same difference 
for AMs was in the region of 1.5s. This interaction although not reliable still showed substantial differences in processing times. Autobiographical memory retrieval times have often been found to contain a high degree of variance and this is because of the complexity of the generation process (Conway \& Pleydell-Pierce, 2000). It may be that this complexity and the variability gives rise to particular problems in detecting differences between different classes of AMs, e.g. AMs versus IFAMs. Therefore, performance on a secondary task may be more informative than generation time about IFAM/AM differences, as was found in the present experiment.

Other findings replicated those of Justice, et al., (2012). Most interestingly, IFAMs were once again found to contain similar numbers of observer and field perspective memories compared to AMs that were strongly dominated by field perspective, AMs were found to be more vivid than IFAMs, and IFAMS contained more motion words than AMs. This latter difference is also thought to indicate increased cognitive effort as motion words allow for quick and simple descriptions that do not require cognitively complex evaluations such as "think", and "feel" (Newman, Pennebaker, Berry, \& Richards, 2003). One way to deal with the increased cognitive load in generating IFAMs may, then, be to represent them in terms of actions that are less cognitively demanding than other types of knowledge, e.g. thoughts, feelings, and emotions. One finding that was not replicated across studies was that of retention interval. In Justice, et al., (2013) we found that IFAMs were placed further in the past i.e. they had a larger retention interval than AMs. This was not found in the present study and may indicate that retention interval is not a useful or valid cue for distinguishing AMs from IFAMS. 
Overall the pattern of mixed memory perspectives, lower vividness, and linguistic indications of increased cognitive effort appears to be emerging as an indicator of intentionally false memories. Taken together, the findings overall, and especially the pattern of differences on recall of a concurrent memory load, all indicate increased cognitive effort in generating IFAMs. This research, to our knowledge, is the first to empirically demonstrate this. We suggest, in line with our previous reasoning, that the increased effort lies in editing an AM as it is generated or once it is fully constructed. We also suggest that identifying differences between true and false memories, at least in their generation phase, might best be achieved indirectly, by evaluating performance on a related concurrent task. 


\section{$\underline{\text { Acknowledgements }}$}

Data were collected at the University of Leeds, UK. Martin Conway was supported by an Economic and Social Research Council project grant, RES-189-250226, and Lucy Justice by a University of Leeds, Institute of Psychological Sciences postgraduate grant. Both authors thank the institution for its support. Electronic mail correspondence can be directed to the Martin Conway at: Martin.Conway.1@ @ity.ac.uk 


\section{$\underline{\text { References }}$}

Blandón-Gitlin, I., Fenn, E., Masip, J., \& Yoo, A. H. (2014). Cognitive-load approaches to detect deception: searching for cognitive mechanisms. Trends in Cognitive Sciences, 18(9), 441-444. http://doi.org/10.1016/j.tics.2014.05.004

Cabeza, R., \& St Jacques, P. (2007). Functional neuroimaging of autobiographical memory. Trends in Cognitive Sciences, 11(5), 219-227. http://doi.org/10.1016/j.tics.2007.02.005

Conway, M. A. (2005). Memory and the self. Journal of Memory and Language, 53(4), 594-628. http://doi.org/10.1016/j.jml.2005.08.005

Conway, M. A. (2009). Episodic memories. Neuropsychologia, 47(11), 2305-13. http://doi.org/10.1016/j.neuropsychologia.2009.02.003

Conway, M. A., \& Pleydell-Pearce, C. W. (2000). The construction of autobiographical memories in the self-memory system. Psychological Review, 107(2), 261-88.

Gil-Gomez de Liano, B., \& Botella, J. (2010). Concurrent Memory Load Can Make RSVP Search More Efficient. Psicologica: International Journal of Methodology and Experimental Psychology, 32(1), 13-30.

Heaver, B., \& Hutton, S. B. (2011). Keeping an eye on the truth? Pupil size changes associated with recognition memory. Memory (Hove, England), 19(4), 398-405. http://doi.org/10.1080/09658211.2011.575788

Justice, L. V, Morrison, C. M., \& Conway, M. A. (2013). True and intentionally fabricated memories. Quarterly Journal of Experimental Psychology (2006), 66(6), 1196-1203. http://doi.org/10.1080/17470218.2012.734832

Newman, M. L., Pennebaker, J. W., Berry, D. S., \& Richards, J. M. (2003). Lying Words: Predicting Deception from Linguistic Styles. Personality and Social Psychology Bulletin , 29 (5), 665-675. http://doi.org/10.1177/0146167203029005010

Pennebaker, J. W., Francis, M. E., \& Booth, R. J. (2001). Linguistic inquiry and word count: LIWC 2001. Mahway: Lawrence Erlbaum Associates, 71, 2001.

Polage, D. C. (2004). Fabrication deflation? The mixed effects of lying on memory. Applied Cognitive Psychology, 18(4), 455-465. http://doi.org/10.1002/acp.995

Vrij, A. (2014). Eliciting verbal and nonverbal cues to deceit by outsmarting the liars. In T. Perfect \& D. Lindsay (Eds.), The SAGE handbook of applied memory (pp. 675695). London: SAGE Publications Ltd.

Vrij, A., Fisher, R., Mann, S., \& Leal, S. (2008). A cognitive load approach to lie 
detection. Journal of Investigative Psychology and Offender Profiling, 5(1-2), 3943. http://doi.org/10.1002/jip.82

Walczyk, J. J., Igou, F. P., Dixon, A. P., \& Tcholakian, T. (2013). Advancing Lie Detection by Inducing Cognitive Load on Liars: A Review of Relevant Theories and Techniques Guided by Lessons from Polygraph-Based Approaches. Frontiers in Psychology, 4, 14. http://doi.org/10.3389/fpsyg.2013.00014

Walczyk, J. J., Schwartz, J. P., Clifton, R., Adams, B., Wei, M., \& Zha, P. (2005). Lying person-to-person about life events: A cognitive framework for lie detection.

Personnel Psychology, 58, 141-170. http://doi.org/10.1111/j.17446570.2005.00484.x 


\section{$\underline{\text { Appendices }}$}

$\underline{\text { Cue words presented to participants }}$

Going to a restaurant

Attending a lecture

Getting up in the morning

Grocery shopping

Visiting a doctor

Going to see a film at the cinema

Going to a party

Going to the bank

Making a meal

Doing an exam

Getting a train

Going on holiday

Going to the hairdressers

Going to a nightclub

Taking a drive

Getting a bus 
Table 1. Means and standard deviations of a memory recall/image generation times, recollective qualities and linguistic features of true and fabricated memories.

\begin{tabular}{lllll}
\hline Memory Feature & AM with & IFAM with & AM without & IFAM without \\
& Load & Load & Load & Load \\
\hline Memory Recall/Image & $9708(9272)$ & $13794(16395)$ & $8275(6392)$ & $11803(12660)$ \\
Generation Time * & & & & \\
Vividness (1-7) ** & $5.3(1.0)$ & $4.3(1.2)$ & $5.4(1.2)$ & $4.2(1.2)$ \\
Retention Interval & $3.1(3.0)$ & $3.4(2.8)$ & $3.3(3.1)$ & $3.5(2.3)$ \\
Account Length & $377(187)$ & $334(194)$ & $371(159)$ & $3.5(1.0)$ \\
Motion Words * & $2.9(0.9)$ & $3.6(1.2)$ & $3.4(1.1)$ & $13.6(3.2)$ \\
Six Letter Words & $14.5(3.1)$ & $13.7(2.6)$ & $13.3(2.9)$ & \\
\hline$* 0001 * \mathrm{p}<0.05$ & & & & \\
\hline
\end{tabular}


Table 2. Number of memories recalled with field and observer perspectives

\begin{tabular}{lll}
\hline Memory Type & Field & Observer \\
\hline AM Load & 95 & 29 \\
AM No Load & 90 & 34 \\
\hline IFAM Load & 54 & 70 \\
IFAM No Load & 58 & 66 \\
\hline Total AM & 185 & 63 \\
Total IFAM & 112 & 136 \\
\hline
\end{tabular}


Page 20

Figure 1. Trial presentation order with no concurrent memory load.

RECALL
NO
NUMBER
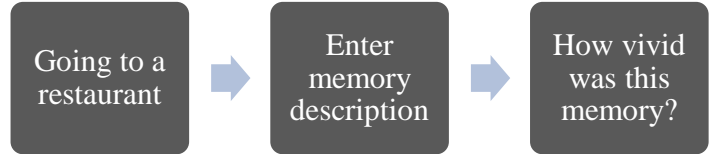

From what

perspective

At what age

do you see

yourself?

did this

event

occur? 
Page 21

Figure 2. Trial presentation order with a concurrent memory load.

RECALL

WITH
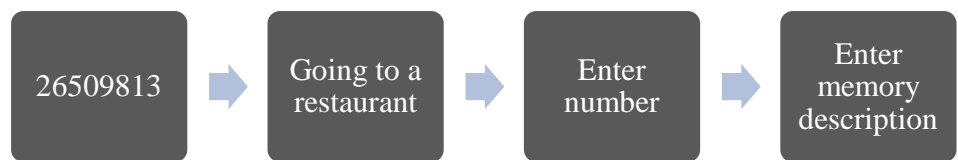

How vivid 
Figure 3. Mean number of all eight digits recalled in serial order for AMs and IFAMs.

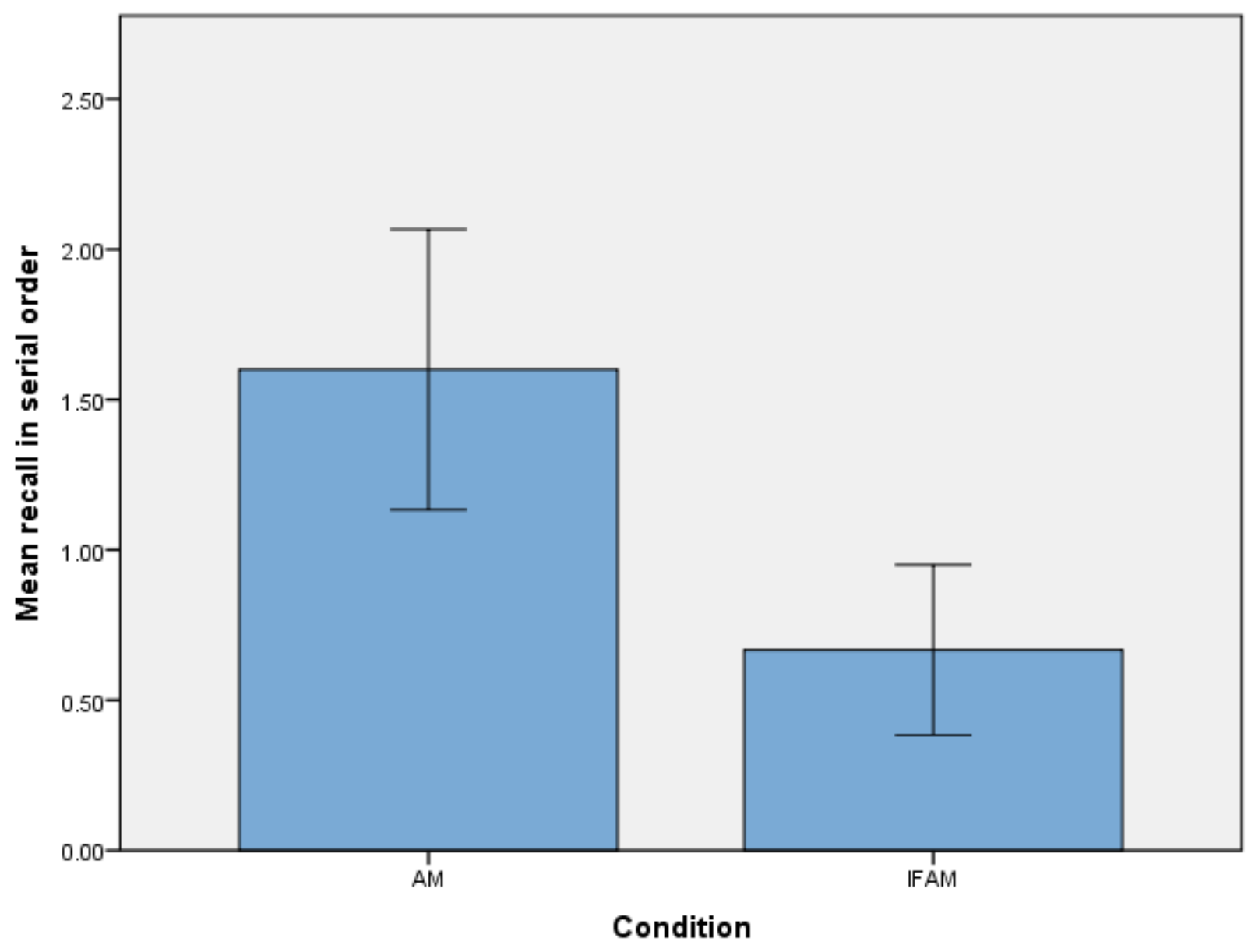

Error Bars: $95 \% \mathrm{Cl}$ 
Figure 4. Mean time taken to input the secondary task digits in AM and IFAM conditions.

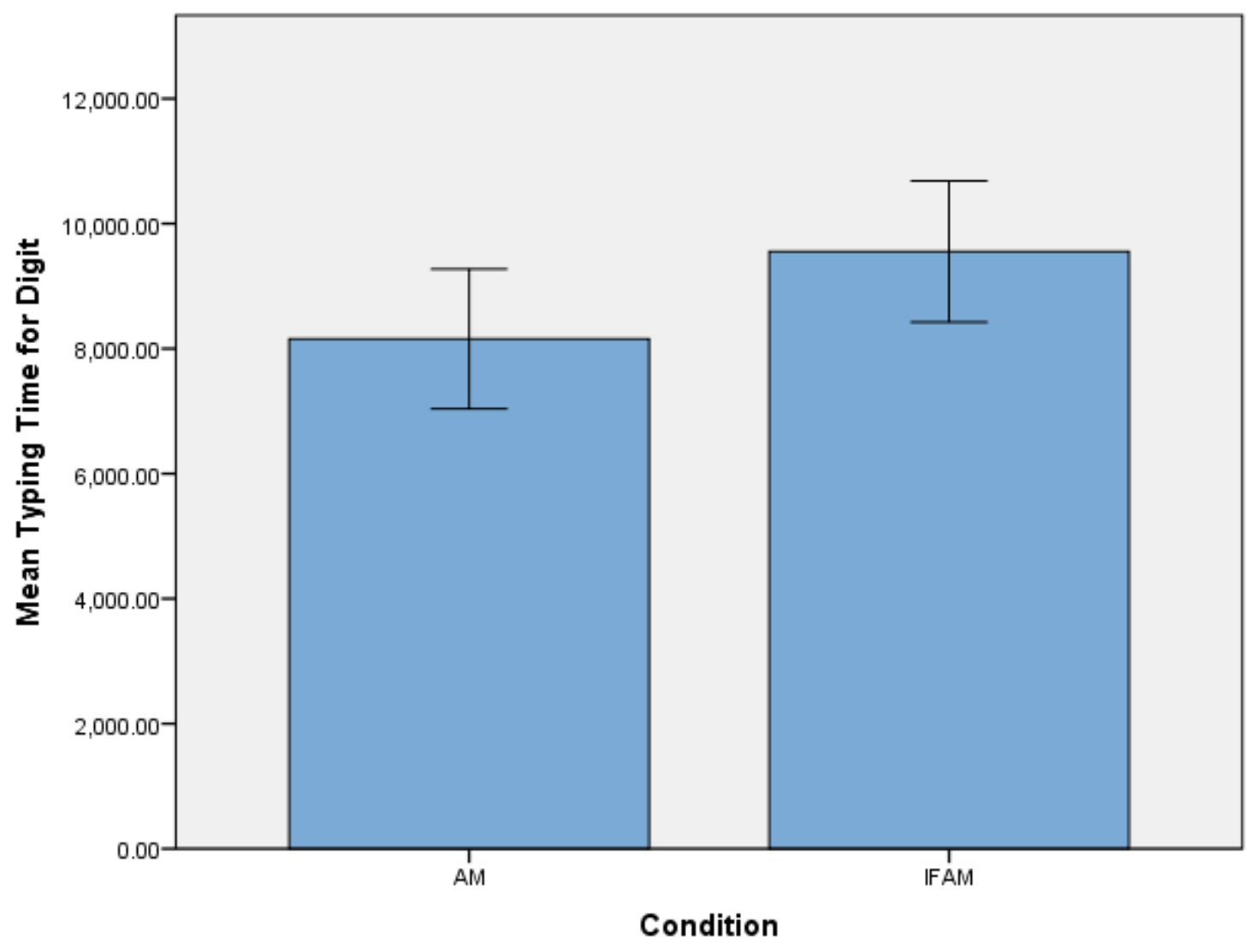

Error Bars: $95 \% \mathrm{Cl}$ 